\title{
Entre el biznes y el arte: el sistema de estrellas y el teatro empresarial en el circuito teatral judio de Buenos Aires
}

\section{Between Biznes and Art: The Star System and Business Theater in the Jewish Theater Circuit of Buenos Aires}

Artículo recibido el 9 de septiembre de 20I9; devuelto para revisión el I8 de mayo de 2020; aceptado el 23 de junio de 2020; https://doi.org/IO.2220I/iie.I8703062e.202I.II8.2742.

Paula Ansaldo Universidad de Buenos Aires-Instituto de Artes del Espectáculo/Consejo Nacional de Investigaciones Científicas y Técnicas/ Núcleo de Estudios Judíos, paulansaldo@hotmail.com, https://orcid. org/0000-0002-9105-5431.

Líneas de investigación Teatro argentino; historia del teatro; teatro judío.

Lines of research Argentine theater; history of theater; Jewish theater

Publicación más relevante Compilación y participación autoral en el libro: Teatro independiente. Historia y actualidad (Buenos Aires: Ediciones del CCC, 20I7).

Resumen En 1930 comenzó en Buenos Aires la época dorada del teatro judío en Argentina. Sin embargo, ya desde las primeras décadas del siglo xx, el desarrollo del circuito teatral en ídish (yidis) se organizó en función de un sistema de estrellas por el cual los empresarios traían a importantes figuras del exterior que, con su fama y prestigio, despertaban el interés de las masas judías porteñas y les garantizaban un éxito seguro de la temporada. Para algunos, la visita de las estrellas era lo que permitía la supervivencia y el crecimiento del teatro judío en Buenos Aires, para otros, era la responsable de que no se pudiera desarrollar un teatro judío-argentino que fuera impulsado por artistas locales. En este trabajo indagaremos en los debates y cuestionamientos que se generaron en torno al "star system", así como en el modo de funcionamiento del teatro empresarial judío.

Palabras clave Teatro judío; Buenos Aires; sistema de estrellas; teatro argentino; ídish.

Abstract In 1930, Buenos Aires witnessed the beginning of the golden age of Jewish theater in Argentina. However, from the first decades of the twentieth century, the development of the theatrical circuit in Yiddish was organized on the basis of a "star system" under which impresarios 
brought important figures from abroad who, with their fame and prestige, roused the interest of the capital's Jewish masses and guaranteed the sure success of the season. For some, the visit of the stars was what enabled the Jewish theater in Buenos Aires to survive and grow; for others, it impeded the development of an Argentine-Jewish theater driven by local artists. This article investigates the debates and questionings that were generated around the "star system", as well as the mode of functioning of the Jewish commercial theater.

Keywords Jewish theater; Buenos Aires; star system; Argentine theater; Yiddish. 


\author{
PAULA ANSALDO \\ UNIVERSIDAD DE BUENOS AIRES-INSTITUTO DE ARTES DEL ESPECTÁCULO \\ CONSEJO NACIONAL DE INVESTIGACIONES CIENTÍFICAS Y TÉCNICAS \\ NÚCLEO DE ESTUDIOS JUDÍOS
}

\title{
Entre el biznes y el arte: \\ el sistema de estrellas y el teatro empresarial en el circuito teatral judio de Buenos Aires
}

\section{Introducción}

ste trabajo se centra en el desarrollo del circuito teatral judío de Buenos
Aires en el periodo de 1930 a 1950 , en el cual se consolidan el sistema de
sestrellas y el modo de producción empresarial. Si bien su comienzo suele
situarse en I9or con la representación en el Teatro Doria de la opereta cómica
El tartamudo de Abraham Goldfaden, ${ }^{1}$ este teatro tiene su mayor crecimiento
en la década de los años treinta, cuando Buenos Aires se posiciona como un
centro teatral judío de importancia internacional. Durante su época dorada,
que se extendió hasta entrados los ańos cincuenta, en la ciudad llegaron a fun-
cionar hasta cinco teatros que representaban todas sus obras completamente
en ídish - la lengua hablada por la mayoría de la población judía de Europa
Oriental hasta la segunda guerra mundial— ${ }^{2}$ por lo que estaban dirigidas espe-

I. Samuel Rollansky, "Dos yídishe gedrukte vort un teater in Argentine" [El periodismo, las letras y el teatro judíos en la Argentina], en Cincuenta años de vida judía en la Argentina (Buenos Aires: Comité de Homenaje a El Diario Israelita, 1940); T. Beylin, "Tzu der geshikhte funen yidishn teater in Arguentine" [Historia del teatro ídish en Argentina], en Argentina. Cincuenta años de vida judia en el país (Buenos Aires: XX Aniversario del Di Presse, 1938).

2. En 1908, en la conferencia de Chernowitz, el ídish fue declarado una lengua nacional del pueblo judío. 


\section{DOI: https://doi.org/10.22201/iie.18703062e.2021.118.2742}

cíficamente al público judío de origen ashkenazí. ${ }^{3}$ Si bien la ciudad ya había recibido la visita de estrellas extranjeras en años anteriores, es a partir de la década de los años treinta cuando las más reconocidas figuras del teatro judío de Estados Unidos y Europa — tales como Jacob Ben-Ami, Maurice Schwartz y Joseph Buloff - comienzan a incluir a Buenos Aires como destino predilecto en sus giras internacionales.

Abordaré el funcionamiento del circuito teatral judío en ídish que se consolidó en Buenos Aires en la década de los años treinta, centrándome especialmente en el modo de producción empresarial ${ }^{4} \mathrm{y}$ en el afianzamiento de un sistema de estrellas. A lo largo del artículo, plantearé preguntas tales como: ¿Quiénes fueron los actores y actrices que se presentaron en Buenos Aires durante este periodo? ¿De dónde provenían? ¿Qué tipos de obras brindaban? ¿Qué alcances tenía la llegada de artistas extranjeros para los artistas locales? ¿Cómo funcionaba el sistema de estrellas? ¿Qué oposiciones y respuestas a este sistema se desarrollaron?

Para responder a estas preguntas, me apoyaré en los materiales históricos de la época, como también en las memorias de quienes fueron los protagonistas del fenómeno que estudio, tanto a partir de los testimonios generados para esta investigación como de los preexistentes, poniéndolos en diálogo con el acervo archivístico y los materiales documentales obtenidos.

Será necesario, para comprender mejor el fenómeno que analizo, tener en cuenta que el teatro judío en ídish que se desarrolló en la Argentina formaba

3. Es necesario aclarar que la inmigración judía que llegó a Argentina desde finales del siglo xx estuvo compuesta por judíos de origen ashkenazí, es decir, aquellos provenientes de Europa del Este y Rusia, cuya lengua era el ídish, y de Europa Central, de habla alemana o húngara, pero también de judíos sefaradíes, que venían de diferentes países de Medio Oriente y hablaban árabe o ladino. Sin embargo, en este trabajo me centraré únicamente en el universo cultural de los judíos ashkenazíes, debido a que fueron quienes llevaron adelante una práctica teatral sostenida y conformaron un circuito teatral propio destinado al público judío, mientras que entre los sefaradíes no encuentro desarrollo de formas teatrales durante el periodo que estudio. Por otra parte, las representaciones en español dentro de este circuito sólo aparecen ya entrada la década de los ańos cincuenta, fuera del periodo elegido. Por estas razones, cuando en este trabajo utilizo la denominación teatro judio o circuito teatral judio me estoy refiriendo al teatro desarrollado en lengua ídish.

4. Utilizo la noción de teatro empresarial para referirme a los teatros donde eran los empresarios quienes se hacían cargo de los costos para llevar adelante la temporada teatral. Uso la categoría de teatro empresarial, en lugar de la de teatro comercial, ya que la tensión entre los intereses comerciales y los artísticos será una constante en los teatros judíos durante el periodo que estudio, mientras que lo que los singularizará será el hecho de estar manejados por empresarios. 
parte de una red cultural transnacional, una red interconectada de comunidades de ídishparlantes alrededor del mundo que constituía una audiencia global, no confinada por las barreras idiomáticas o geográficas que limitaban a los teatros nacionales. Así, el teatro judío —al igual que las publicaciones periódicas y los libros- operaba más allá de los bordes nacionales. Esto provocó que los directores, actrices y actores judíos trabajaran de manera itinerante, desplazándose y viajando permanentemente entre los diferentes centros teatrales judíos del mundo: de Varsovia a París, de Vilna a Nueva York, de Londres a Buenos Aires. En este sentido, parto de la perspectiva de la historia transnacional, para la cual el teatro judío de este periodo es una de las denominadas prácticas transnacionales, es decir "prácticas que atraviesan fronteras estatales pero que no surgen necesariamente de agencias o actores estatales, y que pueden operar en tres ámbitos: el económico, el político y el cultural". 5 La historia transnacional indaga en la múltiple variedad de relaciones, lazos e interacciones que vinculan a personas e instituciones más allá de las fronteras de los Estados-nación. Al respecto, Leonardo Senkman y Judit Bokser Liwerant afirman que:

los judíos oriundos de Europa oriental, especialmente Polonia, lograron establecer entre ambas guerras mundiales relaciones transnacionales de centro-periferia que influyeron poderosamente en la construcción de una nueva diáspora ídishparlante etno-transnacional en Buenos Aires. ${ }^{6}$

Por esta razón, esos autores proponen un acercamiento al estudio de la vida judía en América Latina en términos de la interacción entre las dimensiones nacional y transnacional.7 En esta misma línea, Alejandro Dujovne postula que, para comprender los modos de circulación y producción del libro (podríamos decir, del teatro) judío es preciso "inscribirlos en una geografía transnacional y en una historia de larga duración". ${ }^{8}$

5. Darina Martykanova y Florencia Peyrou, eds., Revista Ayer. La Historia Transnacional 2, núm. 94 (20I4): I3.

6. Judit Bokser Liwerant y Leonardo Senkman, "Diásporas y transnacionalismo. Nuevas indagaciones sobre los judíos latinoamericanos hoy", Judaica Latinoamericana, núm. 7 (2013): 24.

7. Judit Bokser Liwerant desarrolla el binomio nacional/transnacional en su artículo "Being National-Being Transnational: Snapshots of Belonging and Citizenship", en Mario Snzajder, Carlos Forment y Luis Roniger, eds., Shifting Frontiers of Citizenship: the Latin America Experience (Leiden y Londres: Brill, 2013), 343-365.

8. Alejandro Dujovne, Una historia del libro judio. La cultura judía argentina a través de sus editores, libreros, traductores, imprentas y bibliotecas (Buenos Aires: Siglo XXI, 20I4), 29. 


\section{DOI: https://doi.org/10.22201/iie.18703062e.2021.118.2742}

De esta forma, reflexionar sobre la circulación transnacional del teatro judío implica, necesariamente, partir de un abordaje cartográfico como el que propone el teatro comparado, la disciplina que estudia "los fenómenos teatrales desde el punto de vista de su manifestación territorial (planeta, continente, país, área, región, ciudad, pueblo, barrio, entre otros), por relación y contraste con otros fenómenos territoriales y/o por superación de la territorialidad". 9 Sigo en este aspecto a Dubatti, quien sostiene que la culminación del teatro comparado es la elaboración de una cartografía teatral, es decir, mapas específicos del teatro que constituyen una síntesis del pensamiento territorial sobre el teatro. Esta mirada cartográfica del teatro resulta especialmente útil para indagar en el caso del teatro judío, donde los mapas teatrales no siempre se superponen con los mapas geográfico-políticos de los Estados nacionales, ya que los directores, actrices y actores judíos trabajaban de manera itinerante, desplazándose y viajando con frecuencia entre los diferentes centros teatrales judíos de la diáspora. Esto se debe a que, como señala Dubatti, la territorialidad del teatro compone mapas de geografía teatral que no siempre coinciden con los mapas de la geografía política, sino que dialogan con ellos por su diferencia. En este mismo sentido, María Valeria Emiliozzi entiende el territorio "como una construcción social e histórica formalizada por la materialización de las actividades humanas en un espacio físico determinado, pero que se desplaza por fuera de los límites jurídicos, del espacio material". ${ }^{\text {ro }}$ De esta forma, a pesar de formar parte de un sistema cultural que funcionaba de forma transnacional, el teatro judío de Buenos Aires crea su propio territorio específico, a partir del cual establece vínculos con otras territorialidades.

\section{Buenos Aires 1930, capital teatral judia}

A partir de la década de los años treinta, Buenos Aires se afianza como un centro teatral judío de importancia internacional, debido a una serie de múltiples factores. En primer lugar, durante el periodo de entreguerras y en la segunda posguerra, se asentó en Buenos Aires una gran población de judíos

9. Jorge Dubatti, Introducción a los estudios teatrales. Propedéutica (Buenos Aires: Atuel, 2012), IIO.

Io. María Valeria Emiliozzi, "El territorio hecho cuerpo: del espacio material al espacio simbólico”, Abra, núm. 33 (2013): 20. 
ídishparlantes que llegaron escapando del antisemitismo y las difíciles condiciones de vida en Europa. ${ }^{\text {II }}$ La mayoría de estos inmigrantes tenía ya incorporada la asistencia al teatro como una práctica cultural relativamente habitual dado que en ese entonces existían compañías teatrales judías que se presentaban a lo largo de todo Europa. ${ }^{\mathrm{I2}}$ Como señalan Slavsky y Skura, "en ese mundo de transición cultural, las formas populares contenidas en el teatro ídish constituyeron una fuente de estabilidad que apelaba a fórmulas conocidas por la audiencia". ${ }^{13}$ Para los inmigrantes recién llegados, el teatro resultaba un lugar de encuentro en el cual combatir el desarraigo al recordar las costumbres y tradiciones propias, y compartir la lengua materna. El teatro en castellano no podía cumplir esta función en tanto que la barrera idiomática y la representación de problemáticas con las que el inmigrante judío no se sentía identificado, lo alejaban de las salas teatrales porteñas, impulsándolo a desarrollar su propia cultura teatral local.

Por otro lado, en esos años, el teatro en ídish que se desarrollaba en los principales centros teatrales de la época, tales como Nueva York y Varsovia, empieza a sufrir una fuerte declinación que obliga a los actores y actrices a realizar giras cada vez más extensas en busca de público. En los Estados Unidos esto se debió por un lado a las limitaciones impuestas a la inmigración judía a partir de 1924, que impidió que se renovara el público de los espectáculos; y por el otro, a la asimilación idiomática de las generaciones de jóvenes nacidos en el país que ya se habían integrado culturalmente, de forma tal que el ídish fue perdiendo su lugar como primera lengua entre los judíos estadounidenses. ${ }^{14}$ Estas razones, sumadas a la competencia cada vez mayor de los espectáculos de Broadway, a la aparición del cine sonoro y a la crisis económica de I929, provocaron que la temporada teatral se volviera cada vez más corta y que

II. Se estima que desde I889 hasta I940 llegaron a Argentina más de 225 mil judíos. Véase Fernando Devoto, Historia de la inmigración en la Argentina (Buenos Aires: Editorial Sudamericana, 2004); Haim Avni, Argentina y la historia de la inmigración judia I8I0-1950 (Buenos Aires: Editorial Universitaria Magnes-AMIA, 1983).

I2. Joel Berkowitz y Barbra Henry, eds., Inventing the Modern Yiddish Stage: Essays in Drama, Performance, and Show Business (Detroit: Wayne State University Press, 20I2).

I3. Leonor Slavsky y Susana Skura, "I9or-20Ir. Cien años de teatro idish en Buenos Aires", en Ricardo Feierstein y Stephen Sadow, comps., Recreando la cultura judeoargentina (Buenos Aires: Milá, 2002), 297.

I4. Edna Nahshon, "The Yiddish Theater in America: A Brief Historical Overview”, en Zachary Baker y B. Sohn, eds., The Lawrence Marwick Collection of Copyrighted Yiddish Plays at the Library of Congress: An Annotated Bibliography (Washington: Library of Congress, 2004), i8. 


\section{DOI: https://doi.org/10.22201/iie.18703062e.2021.118.2742}

muchos teatros cerraran, por lo que los actores y actrices optaron por irse de gira a otros lugares del mundo en los cuales las comunidades judías estaban en pleno crecimiento, como era el caso de la Argentina..$^{\text {Is }} \mathrm{Al}$ mismo tiempo, el hemisferio sur se beneficiaba por la oposición de temporadas, de manera tal que en el receso de verano, los actores extranjeros podían viajar a presentarse en Argentina, sin necesidad de abandonar sus propias compañías. Realizaban así dos temporadas de invierno, una en Estados Unidos, y otra en Sudamérica, una con base en Nueva York, y la otra con base en Buenos Aires, desde donde viajaban también a otras ciudades argentinas como Rosario, Córdoba y Santa Fe, y a las colonias judías, así como también a otras ciudades latinoamericanas como Montevideo, Santiago de Chile, San Pablo y Río de Janeiro.

Los años treinta son también el momento en que el teatro judío deja de estar vinculado con los tratantes de blancas. Según han postulado los historiadores, hasta finales de la década de los años veinte muchas de las empresas teatrales judías se sostenían gracias al dinero proveniente de la prostitución. En Buenos Aires, donde la prostitución fue legal entre 1875 y 1936, existió una importante red de trata de blancas - llamada primero Sociedad Israelita de Socorros Mutuos "Varsovia", luego Zwi Migdal— que operó en la Argentina y trajo a cientos de mujeres desde Europa del Este para trabajar en sus prostíbulos. Slavsky y Skura señalan que durante este periodo, los rufianes (como se denominaba a los proxenetas) "invertían su dinero en la producción teatral y las mujeres que explotaban formaban una parte importante de su auditorio"; ${ }^{16}$ Víctor Mirelman sostiene que el auditorio estaba en gran medida compuesto por los rufianes y sus mujeres "que eran el verdadero sostén del teatro"; $;^{17}$ Alan Astro se refiere a la "influencia del dinero sucio en el teatro ídish", ${ }^{18}$ y Nora Glickman afirma que "era bien sabido que los traficantes contaban con el apoyo de las autoridades policiales y que eran los protectores financieros del teatro

15. Nahma Sandrow, Vagabond Stars: A World History of Yiddish Theater (Syracuse: Syracuse University Press, 1995), 87-88.

I6. Leonor Slavsky y Susana Skura, "I9or-20II. Cien años de teatro ídish en Buenos Aires", en Feierstein y Sadow, Recreando la cultura judeoargentina (Buenos Aires: Milá, 2002), 298.

17. Victor Mirelman, En busca de una identidad: los inmigrantes judios en Buenos Aires I89oI930 (Buenos Aires: Milá, 1988), 289.

I8. Alan Astro, "Más allá de la represión: la literatura ídish en América Latina”, en Adriana Huberman y Alejandro Meter, eds., Memoria y representación. Configuraciones culturales y literarias en el imaginario judio latinoamericano (Rosario: Beatriz Viterbo, 2006), 215. 
ídish”. ${ }^{19}$ Como señala Rollansky (1940), fue ese sector de la población judía el primero que consideró al teatro como propio al convertirlo en un espacio de socialización y encuentro. Por su parte, Mir Yarfitz en su trabajo sobre los judíos y el trabajo sexual, ${ }^{20}$ se refiere al teatro ídish de este periodo como un espacio de particular visibilidad para los tratantes de blancas, ya que ofrecían financiación y un público entusiasta para las obras teatrales. De esta forma, la presencia de los proxenetas y sus pupilas en el teatro provocó una serie de nociones entre los judíos de Buenos Aires, que llevaron a identificar al teatro judío con un espacio de inmoralidad e indecencia, no adecuado para familias. Yarfitz sostiene que el público de alguna manera sentía que ponía en riesgo su reputación cuando iba al teatro judío, puesto que temía ser confundido por los no judíos con un proxeneta o una prostituta. ${ }^{21}$ Por su parte, los críticos e intelectuales consideraban que la voluntad de los empresarios por satisfacer a los proxenetas tenía incidencia en la elección de los repertorios y que esto no permitía que el teatro judío dejara de ser un mero entretenimiento para convertirse en una experiencia de mayor interés artístico y cultural. Lo cierto es que, más allá de la influencia concreta que los proxenetas realmente tuvieran, estas ideas desprestigiaban el teatro judío, y alejaban a un importante sector del público de las salas teatrales.

Este proceso comienza a revertirse a partir de 1926, cuando los principales teatros que presentaban obras en ídish prohibieron de manera oficial la entrada a los tratantes de blancas, y por último, en 1930, cuando la Zwi Migdal se disuelve, el teatro judío se libera en definitiva de toda sospecha acerca de influencia prostibularia, lo cual permite que un público más amplio comience a asistir con regularidad al teatro.

Es así que, entre los años treinta y cincuenta, se desarrolla la época dorada del teatro judío en Buenos Aires, donde encontramos cuatro teatros prácticamente destinados en exclusiva a presentar obras en ídish: el Excelsior y el Soleil en el barrio de Abasto, el Mitre en Villa Crespo, el Ombú en el barrio de Once (donde después se construiría el edificio de la Asociación Mutual Israelita Argentina [AMIA] $),{ }^{22}$ y en los años cincuenta, el teatro construido por el Idisher

19. Nora Glickman, La trata de blancas (Buenos Aires: Pardes, 1984), 50.

20. Mir Yarfitz, Impure Migration: Jews and Sex Work in Golden Age Argentina (New Brunswick: Rutgers University Press, 2019).

2I. Yarfitz, Impure Migration, I26.

22. La Asociación Mutual Israelita Argentina (AMIA) es la organización central de la comunidad judía argentina, situada en la ciudad de Buenos Aires. 


\section{DOI: https://doi.org/10.22201/iie.18703062e.2021.118.2742}

76

PAULA ANSALDO

Folks Teater (IFT) en la calle Boulogne Sur Mer. En ocasiones, se alquilaban también otras salas como las del Teatro Nuevo y el Teatro Coliseo. Además de los teatros, algunos bares presentaban números artísticos y de variedades con temas judíos a la manera del café-concert, tales como El Cristal y El Internacional, con lo que se conformó un amplio y diverso circuito teatral completamente representado en ídish.

Las funciones se daban de martes a domingo, incluso con dos o tres representaciones en un mismo día durante los fines de semana, y las salas se mantenían llenas a lo largo de toda la temporada, que por lo general duraba de abril a noviembre. El público que asistía a los teatros en ídish era heterogéneo: se componía tanto por inmigrantes recién arribados al país, como por judíos que ya desde hacía muchos años residían en Buenos Aires; concurrían tanto los obreros como los judíos más adinerados y aquellos que ya comenzaban a conformar la clase media argentina. Incluso algunas familias viajaban a Buenos Aires desde otras provincias o desde las colonias judías, para asistir a las funciones del teatro judío. ${ }^{23}$

\section{El teatro empresarial y el starismo}

En un testimonio publicado en 1985, Salomón Stramer, uno de los más reconocidos actores y empresarios teatrales del campo teatral judío de Buenos Aires, decía: "como empresarios quisimos tener dos cosas al mismo tiempo: responsabilidad en los biznes $^{24} \mathrm{y}$ buen repertorio, un aporte a la cultura" ${ }^{25}$ Esta frase resume de alguna manera la problemática que afrontó el teatro empresarial en ídish en la Argentina durante su periodo de mayor auge, entre 1930 y 1950: la contradicción entre la búsqueda de rentabilidad comercial, y el deseo de brindar espectáculos de calidad artística. Para los empresarios teatrales no siempre fue posible servir a ambos objetivos y no todos los teatros buscaron satisfacerlos en igual manera, pero a lo largo de los años la polarización entre repertorios de calidad y espectáculos de menor nivel fue creciendo y el rumbo que

23. Reconstrucción a partir de las entrevistas de la autora a espectadores de la época: Moishe Korin, Ángel Goldman y Cacho Lotersztain.

24. Biznes significa negocios y es un anglicismo en ídish.

25. Sara Itzigshon, Ricardo Feierstein, Isidor Niborski y Leonardo Senkman, "Salomón Stramer", Integración y marginalidad. Historias de vidas de inmigrantes judios en Argentina (Buenos Aires: Editorial Pardes, 1985), I8. 
debía tomar el teatro judío de Buenos Aires fue un tema debatido entre los artistas e intelectuales.

Uno de los recursos para atraer al público que resultó más cuestionado fue la utilización del "star system", un sistema de estrellas por el cual los empresarios traían a importantes figuras del exterior que, con su fama y prestigio, despertaban el interés de las masas judías porteñas y les garantizaban un éxito seguro de la temporada. Para algunos, el "star system" era lo que permitía la supervivencia y el crecimiento del teatro judío en Buenos Aires, para otros, era el responsable de que no se pudiese desarrollar un teatro judío-argentino que fuese llevado por artistas locales.

Los empresarios radicados en Argentina — tales como Adolfo Mide o Isaac Nuguer- alquilaban las salas teatrales y traían a distintas figuras extranjeras cada año para encabezar sus compañías, las cuales estaban formadas por artistas locales. Para esto utilizaban su propio capital, asumiendo un gran riesgo económico y recurrían a la venta de entradas anticipadas o de funciones a beneficio para instituciones, que les adelantaban el dinero necesario para costear los gastos de la temporada. ${ }^{26}$ Así, los empresarios teatrales y sus intermediarios tuvieron un importante papel, elaboraron una red de contactos y desarrollaron un sistema de incentivos económicos y simbólicos, que permitieron que se presentaran en la ciudad las más importantes figuras de la época. Se trataba, por tanto, de un sistema que se sostenía mediante la taquilla, razón por la cual estaba fuertemente orientado a satisfacer los gustos del público y garantizar así su asistencia, que era lo que permitía recuperar el dinero invertido.

Mediante este sistema de estrellas, llegaron durante esos años a la Argentina múltiples artistas internacionales, provenientes principalmente de los Estados Unidos y Europa, a los cuales se los denominaba con el término en ídish gastrolir/n, que hacía referencia a su carácter de actores visitantes, o con la palabra proveniente del inglés star. Cada empresario traía tres o hasta cuatro figuras por cada temporada, las cuales se presentaba por algunos meses, y luego le daban lugar a la siguiente star que llegaba del extranjero. Esto creaba una gran competencia entre los empresarios y sus teatros por presentar y posicionar a sus estrellas como las grandes atracciones de la temporada. Para esto, desplegaban estrategias publicitarias por medio de afiches y, en especial, por medio de

26. En sus memorias, el empresario teatral Adolfo Mide relata una serie de anécdotas, en las cuales pueden verse las estrategias utilizadas por los empresarios para conseguir el dinero necesario para financiar la temporada teatral. Adolfo Mide, Epizodn fun idish teater [Episodios del teatro ídish] (Buenos Aires, 1957) (traducción del ídish de León Skura). 


\section{DOI: https://doi.org/10.22201/iie.18703062e.2021.118.2742}

los anuncios y notas en los diarios judíos, donde se daba a conocer a las figuras internacionales que vendrían en cada temporada, se señalaban sus éxitos y las obras en las que habían representado, lo que contribuía a estimular el entusiasmo del público argentino. De esta forma, el interés de los espectadores se nutría de la novedad, ya que el sistema de estrellas implicaba una renovación constante de los actores y actrices, y de las obras de la cartelera, con nuevos estrenos y figuras que cambiaban mes a mes. Durante este periodo, el campo teatral judío de Buenos Aires se encontraba condicionado por el tipo de espectáculos que se presentaban en las ciudades que funcionaban como centros productores del teatro judío mundial: Varsovia, y luego, sobre todo, Nueva York.

En cuanto a los géneros de las obras representadas, la cartelera teatral judía estaba dominada por las operetas, los melodramas y las comedias musicales, que eran el tipo de espectáculos que más éxito tenían entre el público y con mayor difusión en los escenarios de los Estados Unidos y Europa. Se trataba de espectáculos que utilizaban las formas del teatro popular, la música y el baile, con un gran énfasis en el lucimiento del artista, por sobre la complejidad del desarrollo argumental o la profundidad de los temas abordados en las obras. Con este tipo de espectáculos llegaron y triunfaron en la Argentina numerosos actores y actrices de operetas y comedias musicales, tales como Pesach'ke Burstein y Lilian Lux, Molly Picon, Ludwig Satz, Itzhak Feld y Lola Schpilman, Nelly Casman, Menashe Skulnik, Benzion Witler, Jennie Goldstein, Julius y Anna Nathanson y Herman Yablokoff, entre los más destacados, muchos de los cuales se presentaron en repetidas oportunidades en los escenarios judíos de Buenos Aires. ${ }^{27}$

Asimismo, a partir de los años treinta, comenzaron a llegar a Argentina como figuras invitadas, referentes artísticos como Maurice Schwartz, Jacob Ben-Ami y Joseph Buloff, quizá los mayores exponentes del teatro judío de arte. Estos tres artistas en sus repertorios tenían obras de autores internacionales, con versiones al ídish de textos dramáticos de Henrik Ibsen, August Strindberg, Ernst Toller, William Shakespeare, entre otros, y adaptaciones teatrales

27. En sus memorias, Herman Yablokoff afirma haber venido seis veces a Buenos Aires, mientras que Pesach'ke Burstein y Lilian Lux, artistas muy aclamados en Argentina, regresaron tantas veces que en 196I decidieron radicarse por dos años en el país. Véase Herman Yablokoff, Der Payatz: Around the World with Yiddish Theater (Silver Spring, Maryland: Bartleby Press, 1995); Pesach'ke Burstein, What a Life! The Autobiography of Pesach'ke Burstein, Yiddish Matinee Idol [edición en inglés de Geshpilt a Lebn] (Syracuse, Nueva York: Syracuse University Press, 2003). 
de textos de León Tolstoi, Fiódor Dostoievski y Máximo Gorki. En cuanto a las obras provenientes de la dramaturgia judía, escenificaron piezas de Scholem Asch, H. Leivik, Peretz Hirschbein, Osip Dimov y otros autores consagrados del repertorio judío. Este tipo de obras implicaban una diferencia respecto a las operetas y comedias livianas que imperaban en los escenarios judíos del periodo, por lo que la llegada de estos artistas aparecía como una posible fuente de aliento y empuje en favor de la elevación artística y cultural del campo teatral judío de Buenos Aires.

La distinción entre espectáculos serios y livianos no era propia del teatro judío local, sino que reproducía una dicotomía presente ya desde principios del siglo Xx en el campo teatral judío: el shund frente al kunst, dos términos contrapuestos que buscaban establecer una distinción extrema entre formas teatrales consideradas buenas o malas, altas o bajas. Shund era una palabra utilizada por primera vez en I893, por el editor y periodista Abraham Cahan para referirse a lo que él deseaba que fuera un género en desaparición: las novelas populares ídish. La palabra — reapropiada por el campo teatral— connotaba la idea de un arte basura, de bajo nivel, es decir, el teatro liviano de operetas y melodramas, que sólo buscaba entretener y "agradar a Moishe", como solía decir la prensa teatral del periodo, refiriéndose a los espectadores de mente simple, ingenuos y poco cultivados. En oposición, el kunst teater (el teatro de arte) representaba obras de valor literario, provenientes de la dramaturgia judía y del teatro universal, y apelaba no sólo a las emociones, sino al intelecto de los espectadores. ${ }^{28}$

Los actores Ben-Ami, Buloff y Schwartz eran representantes de este movimiento de teatros de arte que ya desde las primeras décadas del siglo xx había combatido la tendencia hacia el shund presente en la escena judía. Por medio de la representación de obras de valor literario y de un gran respeto por el dramaturgo y el texto, este movimiento había perseguido el objetivo de producir arte de acuerdo con un fuerte compromiso estético, por oposición al teatro comercial y su mero interés por la taquilla. Es así que después de la primera guerra mundial comenzaron a aparecer compañías teatrales judías que se autoproclamaban de teatro de arte. En Nueva York, Maurice Schwartz fundó en I9I8 su Yiddish Art Theater (Teatro Judío de Arte), del que formó parte Jacobo Ben-Ami, quien a su vez provenía de la Hirschbein Trupe, la primera

28. Para un mayor desarrollo sobre la oposición shund/kunst véase Paula Ansaldo, "El teatro judío en la polémica shund/kunst: el IFT y el teatro de arte", Panambi. Revista de Investigaciones Artisticas, núm. 8 (2019): 35-42. 


\section{DOI: https://doi.org/10.22201/iie.18703062e.2021.118.2742}

80

PAULA ANSALDO

compañía teatral judía de arte creada en 1908. Por su parte Joseph Buloff y su esposa, Luba Kadison, habían sido miembros de la Vilner Trupe, el epicentro del movimiento de teatros judíos de arte, fundada en $1915 .{ }^{29}$ Estas compañías habían popularizado la obra de una nueva generación de dramaturgos judíos, al poner en contacto al público con nuevos estilos teatrales y textos dramáticos modernos que se diferenciaban del tipo de espectáculos musicales que estaban acostumbrados a ver en los escenarios del teatro comercial.

Por esta razón, la llegada de estos artistas a la Argentina se entendió como una influencia benéfica para el campo teatral local, y el éxito de sus espectáculos se utilizó como prueba de que el público judío de la Argentina pretendía un teatro de un mayor valor literario y artístico, del que los empresarios teatrales solían ofrecerle. Tanto en los testimonios de Maurice Schwartz ${ }^{30}$ como en los de Luba Kadison, ${ }^{3 \mathrm{I}}$ los actores destacan el éxito que tuvieron en Buenos Aires con sus dramas serios, y cómo el público argentino solía ser más receptivo con este tipo de obras que las audiencias judías de otras ciudades. Como señalaba Enrique Feinmann, respecto a la primera temporada de Ben-Ami en Buenos Aires:

el público que va al teatro para distraerse, para olvidar sus propios males, o simplemente a reír, ha preferido ante tan grande comediante la emoción superior de sentir, pensar y de conmoverse. Bien lo dijo Ben Ami en la soirée en su honor: "He procurado siempre que la platea se eleve a mi tinglado de arte y no descender con mi labor artística a la platea". ${ }^{22}$

En este artículo, la labor de Ben-Ami se presenta como un elemento de elevación cultural para las audiencias, al delinear una función específica del arte teatral que supera y va más allá de su carácter de mero entretenimiento. En este mismo sentido, en un comunicado publicado en 1935, con motivo de la segunda presentación de Joseph Buloff y Luba Kadison en Buenos Aires, un

29. Para una historia del movimiento de teatros judíos de arte, y en específico de la Vilner Trupe véase Debra Caplan, Yiddish Empire: The Vilna Troupe, Jewish Theater, and the Art of Itinerancy (Ann Arbor: University of Michigan Press, 20I8).

30. Martin Boris, Once a Kingdom. The Life of Maurice Schwartz and the Yiddish Art Theatre, Museum of Family History, consultado el ro de agosto de 2019, en www.museumoffamilyhistory.com/mschwartz-ok-toc.htm.

3I. Joseph Buloff y Luba Kadison, On Stage Off Stage: Memories of a Lifetime in the Yiddish Theatre (Cambridge: Harvard University, 1992).

32. Enrique Feinmann, "Un homenaje a Ben-Ami”, Revista Comedia 6, núm. 75 (I93I): 42. 
conjunto de intelectuales entre los que se encontraban figuras de gran trayectoria como los escritores César Tiempo, Samuel Glasserman, Maximo Yagupsky y Samuel Feldman, hace un diagnóstico negativo de la situación del teatro judío en Argentina y el mundo, y presenta la llegada de estos artistas como una posible inspiración para el surgimiento de un nuevo tipo de teatro en Buenos Aires:

Durante su primera visita demostraron ya haber logrado electrizar al espectador, encumbrándolo a la altura de su arte, y demostrando que también en el teatro judío la finalidad no es la distracción barata, sino que además de ser un pasatiempo, debe ejercer una función educadora, procurando por ende la elevación del espíritu y el saneamiento del cerebro [...] Es deber de toda la colectividad, y más aún de los amigos del buen teatro judío, interesarse por los espectáculos del binomio Buloff-Kadison, porque el hecho de crear el ambiente propicio puede convertirse en estímulo para considerar la creación de un teatro estable de arte judío en Buenos Aires, en el cual actúe lo mejor que aún poseemos. ${ }^{33}$

Este comunicado resume de alguna forma las aspiraciones de los críticos e intelectuales argentinos, quienes, mientras celebraban la llegada de artistas de gran renombre, no dejaban de abogar por que su trabajo resultara una inspiración para que finalmente se creara en Buenos Aires un teatro judío de arte permanente, impulsado con fuerzas locales.

Cabe distinguir entonces entre dos tendencias presentes en el circuito teatral judío: una de teatro de arte, que se componía por obras literarias que abordaban temáticas serias, que buscaba no sólo divertir sino educar a la audiencia; y otra compuesta por operetas, melodramas y comedias musicales livianas, que se apoyaba en elementos espectaculares como la música y el baile, y cuya principal finalidad era entretener a los espectadores. Si bien los críticos e intelectuales caracterizaban a estos espectáculos como shund, este tipo de obras era sumamente exitoso por lo que, en definitiva, eran las que garantizaban el sostenimiento de la temporada. Constituían, además, una fuente de goce para los trabajadores judíos, a la vez que los ayudaban a sobreponerse a las duras condiciones que enfrentaban como inmigrantes para abrirse paso en la nueva sociedad. Como señala Joel Schechter (2008), las operetas y comedias

33. Archivo Fundación rwo, Llamado a toda la colectividad israelita de Buenos Aires en general y en particular a los amigos del buen teatro, Comité de Recepción a los Eminentes Artistas Joseph Buloff y Luba Kadison, julio de 1935 (extracto). 


\section{DOI: https://doi.org/10.22201/iie.18703062e.2021.118.2742}

82

PAULA ANSALDO

musicales exhibían personajes con sentido del humor, optimismo, perseverancia, y mostraban la habilidad de los judíos para sobrevivir a la pobreza y los prejuicios. Esto era algo que los espectadores de la época necesitaban intensamente recordar, lo cual constituía una de las principales razones que explicaban el absoluto éxito que estas obras tenían entre el público judío de Buenos Aires.

\section{Debates y cuestionamientos en torno al "star system"}

La tensión entre el deseo de mejorar el nivel de la temporada teatral mediante la visita de importantes artistas internacionales, y la preocupación por la dependencia que sufría el campo teatral judío argentino respecto a la llegada de estrellas extranjeras, será una constante en todas las críticas teatrales del periodo. Los intelectuales y periodistas Samuel Rollansky, desde el diario $D i$ Idishe Tzaitung, y Jacobo Botoshansky y L. Zitnitzky desde el diario Di Presse, llamarán constantemente la atención sobre los peligros del "star system", al cual consideraban responsable de la falta de desarrollo del teatro local y de impedir que éste pudiera estabilizarse por sus propios medios. En sus reseñas, Botoshansky señalaba que Argentina contaba con suficientes buenos actores como para permitir el sostenimiento de un teatro permanente, y acusaba a los empresarios de aferrarse sin justificación alguna a la idea de que siempre era necesario traer stars extranjeras para encabezar sus compañías. Por su parte, Rollansky sostenía que:

el teatro, pese al funcionamiento de varias salas permanentes, carece aún de vida propia; mientras que el periodismo y la literatura viven de sus propios elementos locales, no puede decirse que el teatro judío de Buenos Aires pueda existir siquiera algunos meses únicamente con los actores locales que tenemos. Siempre necesita del concurso de los actores del exterior: lo extraño es que algunos actores locales sobrepujan a ciertos astros por su talento y, sin embargo, el fenómeno señalado persiste. La historia de nuestro teatro es por consiguiente la historia de los astros que han pasado por las tablas de Buenos Aires. ${ }^{34}$

34. Rollansky, "Dos yídishe gedrukte vort un teater in Argentine", 85 (la traducción es de Salomón Resnick). 
En opinión tanto de Rollansky como de Botoshansky, la dependencia de los gastrolirn destruía las posibilidades de que surgiera un teatro que reflejara las problemáticas de la población judía de la Argentina, puesto que los actores invitados traían un repertorio propio que no necesariamente interpelaba al público local. Esto se debía a que, en la mayoría de los casos, las estrellas presentaban espectáculos que ya tenían preparados, con papeles que ya conocían y que habían montado antes en Nueva York o en otras ciudades del mundo, lo que provocaba que muchas veces las obras se repitieran de una temporada a otra, o incluso en la misma temporada. Por esta razón, a pesar de que por ese entonces había teatro en ídish en Buenos Aires todos los días, durante toda la semana, ocho meses al año, en 1940 Rollansky todavía se preguntaba si existía un teatro ídish argentino. Esta diferenciación entre un teatro judío argentino y un teatro judío en Argentina donde simplemente se presentaban estrellas extranjeras era recurrente en los escritos del periodo. Los críticos y artistas consideraban así, que no alcanzaba con tener teatro en ídish en Argentina, sino que era necesario crear un teatro ídish argentino, es decir, un teatro propio que pudiera desarrollar sus propias temáticas y características y que no estuviera supeditado y organizado alrededor de las figuras y los repertorios traídos del exterior.

Tanto el empresario Adolfo Mide como Salomón Stramer afirman que durante esos años la discusión en torno a los defectos y beneficios del sistema de estrellas se debatía permanentemente entre los intelectuales y artistas. En palabras de Salomón Stramer:

Lo que más se atacaba era lo que se llamaba Star-System: que los empresarios traíamos figuras del exterior, y con eso les arruinábamos la carrera —así se nos acusaba- a los actores de aquí. Decían que, si un valor de acá nunca recibía papeles importantes, nunca crecía en su arte ni en la popularidad [...] que siempre quedaba en la sombra, tapado por nombres que ya venían con su fama hecha desde antes y de afuera. ${ }^{35}$

Ambos recuerdan los "juicios al star system" como el que relata Mide en sus memorias, sostenido por la Sociedad de Escritores y Periodistas H. D. Nomberg en el Teatro Ombú en 1932, donde intervinieron representantes de los

35. Itzigshon, Feierstein, Senkman y Niborski, "Salomón Stramer", en Integración y marginalidad, 19. 


\section{DOI: https://doi.org/10.22201/iie.18703062e.2021.118.2742}

principales teatros judíos, e intelectuales de los diarios Di Presse y Di Idishe Tzaitung. Mide afirma allí que la necesidad de traer estrellas se debía a la importancia otorgada por la audiencia a la presencia en el teatro de nombres y rostros. Esta misma idea aparece en un panfleto titulado: Far vos gastrolirn? (¿Por qué actores invitados?) firmado por Mide, donde si bien admite que los críticos y los artistas tienen buenas razones para criticar el "star system", justifica seguir trayendo estrellas del exterior de la siguiente manera:

Aunque se cuente con los mejores actores y actrices, si no se recurre al actor extranjero, es imposible mantener una temporada. Y si remotamente se llegara a contar con un mecenas que aporte capital, tampoco tendría éxito en Buenos Aires, pues el público se volcaría al otro teatro que sí tenga actores invitados. ${ }^{36}$

Esto daba lugar a una suerte de círculo vicioso, puesto que la necesidad de atraer una audiencia numerosa, con el fin de recuperar la inversión realizada, provocaba que los empresarios no quisieran asumir riesgos artísticos y buscaran garantizar la asistencia del público contratando figuras que ya tuvieran renombre en el exterior. Por esta razón, elegían no apostar por los nuevos talentos locales, lo que a su vez impedía que surgieran nuevas primeras figuras nacionales que en el futuro pudieran atraer tantos espectadores como lo hacían las estrellas extranjeras. La teoría de los críticos del "star system" era que la llegada constante de nuevos artistas malacostumbraba a los espectadores porteños a ver todo el tiempo nuevos rostros sobre los escenarios, lo cual llevaba a que sólo asistieran al teatro para ver a los stars, que era el elemento sobre el que estaba puesto todo el foco publicitario. Por este motivo, a pesar de que Buenos Aires contaba con una cantidad importante de actores y actrices de mucho talento, los intentos de formar una compañía local estable habían efectivamente fracasado debido a la imposibilidad de sustentarse económicamente. Además, durante los meses que duraba la temporada las figuras internacionales se instalaban en Buenos Aires y parte del placer de sus visitas consistía en compartir el espacio con ellos por fuera de la sala teatral, asistiendo al puerto a su llegada para recibirlos o participando de los encuentros que se realizaban en su honor, es decir, un tipo de actividades y emociones que los actores y actrices nacionales no podían proveer. En este sentido, el escenógrafo del teatro

36. Archivo Fundación Iwo, Adolfo Mide, Far vos gastrolirn? [¿̨or qué actores invitados?] (la traducción es de Perla Rozenblum). 
ídish (y futuro presidente del sindicato) Mischa Shvartz afirmaba "que el starismo distorsionaba el criterio estético del público, porque desviaba su atención hacia situaciones novedosas como la llegada de los artistas al puerto y los banquetes en su honor". 37

Por último, los empresarios exigían que las obras se renovaran semanalmente, por lo que el tiempo de los ensayos era muy breve, y resultaba insuficiente para que los artistas locales trabajaran lo necesario en su papel, como para poder transmitir la complejidad que los personajes de las obras de mayor calidad requerían. Esta exigencia de los empresarios argentinos puede verse en las cartas enviadas por los artistas: Schwartz, por ejemplo, señala que, en su primera temporada en Buenos Aires, permaneció diez semanas y montó trece espectáculos. Por su parte Buloff indica que en su segunda temporada se quedó ocho semanas en Buenos Aires, poniendo en escena nueve obras. La presión de los administradores de los teatros para sacar el mayor provecho posible durante la estancia de las estrellas extranjeras atentaba contra la calidad de las obras, y en especial contra las actuaciones de los artistas locales, que a diferencia de las estrellas que ya tenían sus papeles estudiados, tenían que componer los distintos personajes con muy poco tiempo de preparación. La dificultad que presentaba para ellos la brevedad de los ensayos aparece en numerosos documentos de la época, como por ejemplo en las memorias de la actriz Zina Rapel,,$^{38}$ radicada en Buenos Aires. Esto obligaba a los artistas a someterse a largos periodos de ensayos, que según los testimonios de la época eran de alrededor de doce horas por día y, por otro lado, afectaba los resultados artísticos de las obras, y en particular la actuación de los actores y actrices locales, que eran quienes menor tiempo tenían para prepararse.

Sin embargo, el problema no era sólo de carácter artístico, sino también económico, puesto que los actores y actrices que residían de manera permanente en Argentina carecían de estabilidad laboral y económica ya que, por lo general, dependían de la llegada de las estrellas y de la posibilidad de formar parte del elenco que las acompañara. Las compañías se formaban y se desarmaban

37. Silvia Hansman y Susana Skura, "Debates en torno a la legitimación del repertorio del teatro ídish argentino (1930-1955)", en Susana Skura y Silvia Glocer, comps., Teatro idish argentino (I930-I950) (Buenos Aires: Universidad de Buenos Aires-Facultad de Filosofía y Letras, 2016), 73 .

38. Las memorias de Zina Rapel las publicó Nehemías Zucker después de la muerte de la actriz, bajo el título Fir doyres idish teater: di lebns-geshikhte fun Zina Rapel/Cuatro generaciones de teatro israelita (Buenos Aires: Eygener Farlag, 1944). 


\section{DOI: https://doi.org/10.22201/iie.18703062e.2021.118.2742}

de temporada a temporada y durante los meses de verano los ingresos eran muy bajos o nulos. Además, mientras que los gastshpilers iban a porcentaje, los actores nacionales cobraban un sueldo fijo, por lo que independientemente del éxito que tuvieran las obras en las que participaban, no podían con esto compensar las pérdidas durante los meses de inactividad. Es así que para defenderse de las políticas de los empresarios y combatir la inestabilidad laboral imperante, se constituyó en 1932 un sindicato de actores: Idishn Aktiorn Fareyn o Sociedad de Actores Israelitas en Argentina. Si bien ya había habido intentos anteriores de constituir una organización de ese tipo, es en 1932 cuando finalmente se logra establecer un sindicato firme y con capacidad suficiente para regular la profesión.

La Sociedad estableció una serie de normas que los empresarios debían acatar y que estaban destinadas a mejorar las condiciones laborales de los trabajadores teatrales: se establecía un sueldo mínimo para los actores y actrices, y una cantidad mínima de integrantes que debía tener cada elenco, fijado en doce miembros. Estos elencos debían contar por obligación con artistas asociados al Fareyn, ninguno de los cuales podía interpretar más de un papel por obra. Además, los contratos no podían realizarse por menos de seis meses y los actores debían recibir su paga cada diez días. Estas regulaciones tenían por objetivo aumentar el índice de empleo de los artistas argentinos y brindarles mayor estabilidad económica. Como contrapartida, se trataba de contratos exclusivos que obligaban a los artistas a trabajar únicamente para la empresa con la que firmaban durante el tiempo que duraba el contrato.

Por otro lado, el reglamento establecía en su Art. I5: "Las empresas no podrán contratar primeras figuras del extranjero, hasta más de tres personas y con contrato de 3 meses", ${ }^{39}$ limitando así el porcentaje de stars que podían integrar los elencos. Estas medidas buscaban contrarrestar el monopolio que las estrellas invitadas tenían de la escena, al regular las visitas extranjeras y brindar así mayores posibilidades de trabajo a los actores y actrices locales. A su vez, el reglamento establecía un porcentaje del sueldo que las figuras extranjeras debían abonar a la Sociedad: tres por ciento de sus ganancias si trabajaba por porcentaje, dos por ciento si estaba contratado a sueldo. Dado que gran parte de los beneficios de la temporada se destinaban efectivamente a pagar los honorarios de las estrellas extranjeras, esta medida garantizaba que por lo

39. Archivo Fundación rwo, Reglamento interno de la Empresa y base de trabajo de la Sociedad de Actores Israelita en la Argentina, Sociedad de Actores Israelita en la Argentina. 
menos una parte de las ganancias del teatro judío argentino se utilizara para mejorar las condiciones de trabajo de los artistas nacionales. Para garantizar el cumplimiento de estas obligaciones, se estipulaba que todo contrato firmado entre la empresa y los intérpretes debía estar confirmado por la Sociedad. Es por esa razón, que en numerosos contratos de la época encontramos la leyenda: "Este contrato tendrá su efecto siempre que la Sociedad de Actores Israelitas lo apruebe", ${ }^{\circ}$ lo cual demuestra el cumplimiento efectivo de esta normativa. La Sociedad funda en 1940 una Caja de Ayuda Mutua, destinada a socorrer a los artistas ancianos, enfermos y desocupados. Para sostenerla, se acuerda un aumento de 5 centavos en el precio de las entradas, que estaría reservado para financiar el proyecto. El reglamento lo firman los empresarios del Soleil, el Mitre, el Ombú y el Excelsior, tres representantes del Aktiorn Fareyn y su gerente, Nehemías Zucker. Es así que, gracias a este tipo de medidas, el oficio teatral fue profesionalizándose y convirtiéndose en una práctica seriamente regulada, con una institución comprometida en impedir abusos y garantizar de esta forma un ejercicio digno de la profesión.

El exitoso funcionamiento del sindicato y la mayor estabilidad de la práctica teatral, sumados al crecimiento del antisemitismo en Europa y, luego, a la llegada de la guerra, provocaron que desde mediados de la década de los años treinta se establecieran en Argentina muchos de los artistas que durante los años anteriores habían venido como figuras invitadas a Buenos Aires, dándole así un impulso mayor al campo teatral local. ${ }^{41}$ Éste fue el caso de Salomón y Clara Stramer, quienes se presentaron primero en Buenos Aires como estrellas invitadas durante la primera mitad de los años treinta. Sin embargo, con el fortalecimiento del antisemitismo en Europa decidieron emigrar, y en 1934 se les contrató para trabajar de manera estable en el Teatro Soleil por Adolfo Mide, quien empleó también a las hermanas de Clara: Ana Feldbaum, y su marido Israel Feldbaum, y Elsa Rabinovitch junto con su hija Margot Steinberg. Se establecieron así definitivamente en Argentina, y pasaron a integrar

40. Archivo Fundación rwo, Contratos, Sociedad de Actores Israelita en Argentina.

4I. Silvia Glocer señala que en 1933 el régimen nazi sancionó la Ley para la Restauración de la Administración Pública Profesional (Gesetz zur Wiederherstellung des Berufsbeamtentums) que, entre otras medidas, prohibía a los no arios ejercer cargos en la función pública, lo cual dejó sin trabajo a una gran cantidad de músicos judíos que trabajaban en instituciones estatales como orquestas, teatros de ópera, conservatorios y universidades. Para un mayor desarrollo véase Silvia Glocer, Melodias del destierro. Músicos judios exiliados en Argentina durante el nazismo (1933-1945) (Buenos Aires: Ediciones Gourmet Musical, 2016). 


\section{DOI: https://doi.org/10.22201/iie.18703062e.2021.118.2742}

las compañías teatrales locales, en las cuales ocuparon los principales papeles secundarios en los elencos que secundaban a las estrellas invitadas. También se radicaron en Argentina los actores y cantantes Max Perlman y Gita Galina, quienes tuvieron un gran éxito entre el público judío porteño. ${ }^{42}$

Por otro lado, comenzaron a constituirse compañías locales, y muchos actores y actrices que ya estaban radicados en la Argentina devinieron también en administradores, al tomar a su cargo la gerencia de teatros que antes estaban regenteados por empresarios, tales como el Soleil, hasta entonces a cargo del abogado estadounidense Charles V. Groll. En 194I, Groll había intentado fundar un teatro judío de arte en Buenos Aires y le había propuesto a Maurice Schwartz radicarse parcialmente en Argentina durante los seis meses que durara la temporada para encabezar una compañía teatral estable en el Teatro Soleil. Este proyecto fue publicitado en los diarios y el mismo Schwartz anunció que tenía la intención de sentar las bases para un Teatro de Arte en Argentina, a la manera de su Yiddish Art Theater de Nueva York. Sin embargo, el proyecto nunca se llevó a cabo, y tan sólo unos años después el Soleil pasó a las manos de los actores Salomón Stramer, Mauricio Peltz, Israel Feldbaum y León Narepkin, quienes fundaron en 1945 la Empresa Soleil. Con motivo de su trigésimo aniversario en 1957 editaron un boletín conmemorativo que sostenía:

Trece años hace de aquel preciado instante en que verdaderos luchadores del teatro se dieron por el teatro en sí; trece años de que el Soleil dejó de ser una sala más, para pasar a ser rector de 'idishkayt'; trece años en que arte y judaísmo se confundieron en una sincera expresión. ${ }^{43}$

Puede verse cómo el Soleil buscó posicionarse como un teatro de buen nivel artístico, que pudiera responder a las necesidades culturales de la población judía argentina, y logró durante esos ańos, que la comunidad teatral lo considerara como un espacio de mayor calidad que sus competidores. ${ }^{44}$

42. Las canciones del autor pueden encontrarse en: Susana Skura y Lucas Fiszman, "Juegos de lenguaje/juegos por dinero en tres canciones de Max Perlman”, en Skura y Glocer, comps., Teatro idish argentino (1930-1950).

43. Archivo Fundación Iwo, Empresa Soleil, Trigésimo Aniversario del Teatro Soleil en Buenos Aires (1945-1957).

44. En las entrevistas realizadas a espectadores del periodo aparece recurrentemente la idea de que el Soleil era un teatro de mejor calidad en relación con el Mitre. En una entrevista reali- 
Sin embargo, a pesar del crecimiento que experimentó el campo teatral local durante esta etapa, los principales obstáculos que afrontaba el teatro judío de la Argentina para lograr sostener una compañía teatral local estable - la dependencia de los empresarios y de las estrellas extranjeras para el sostenimiento de la temporada teatral— continuarán siendo problemas irresolubles, que sólo encontrarán respuesta en el campo teatral independiente, lejos de los empresarios, del "star system", e incluso del Aktiorn Fareyn.45

\section{Palabras finales}

Entre los años treinta y cincuenta Buenos Aires emergió como un polo teatral alternativo que le permitió a los artistas compensar la declinación que la temporada teatral en ídish estaba sufriendo en las ciudades donde hasta entonces habían estado los principales núcleos del desarrollo teatral judío. La oposición de temporadas configuró una dinámica particular que permitió que el crecimiento del circuito teatral de Buenos Aires no compitiera con otros polos de producción, sino que funcionara como un centro teatral adicional y complementario. El afianzamiento de Buenos Aires y la expansión de este circuito teatral hacia otras ciudades latinoamericanas y argentinas les permitió a los artistas, radicados en Europa y luego principalmente en Nueva York, continuar trabajando a contratemporada en el hemisferio sur. En este sentido, los empresarios teatrales fueron verdaderos emprendedores y funcionaron como intermediarios, al organizar redes de contacto e intercambio entre los diferentes centros teatrales judíos del mundo que contribuyeron a desarrollar un circuito teatral judío en Buenos Aires.

No obstante, si bien por un lado el teatro empresarial cumplió un papel fundamental en la consolidación de Buenos Aires como un centro significativo en el mapa teatral judío, por el otro, delineó un modo de organización de la temporada teatral que estuvo principalmente inclinado hacia el vínculo con el exterior. De esta forma, el "star system" posibilitó la llegada de artistas extranjeros que enriquecieron y llevaron al teatro judío de Buenos Aires a una etapa

zada por la autora en noviembre de 20I6, Lidia Goldberg afirmaba que "el Teatro Soleil era un teatro más culto, el Teatro Mitre era shund. Los Stramer no hacían shund".

45. Para un desarrollo sobre el teatro independiente judío en Buenos Aires véase otros artículos de la autora: Paula Ansaldo, "Teatro popular, teatro judío, teatro independiente: una aproximación al Idisher Folks Teater (IFT)”, Culturales, núm. 6 (20I8): I-27. 


\section{DOI: https://doi.org/10.22201/iie.18703062e.2021.118.2742}

90

PAULA ANSALDO

dorada, pero a su vez limitaron sus posibilidades de desarrollar una producción autónoma. Esto se expresó tanto en la conformación de las compañías teatrales profesionales, donde los artistas nacionales ocuparon una posición secundaria respecto a las estrellas invitadas, como también en la configuración de los repertorios. En este sentido, no resulta sorprendente la poca cantidad de obras de dramaturgia nacional que llegaron a los escenarios judíos de la época, y la preeminencia de las temáticas universales por sobre las locales.

A lo largo del trabajo se pudo observar cómo la centralidad del "star system” llevó a la creación de una suerte de círculo vicioso por el cual el público se acostumbró a la novedad permanente y comenzó a demandar un recambio constante de nombres y rostros. El modo de producción empresarial, orientado fuertemente hacia fines comerciales, dependió así por completo del "star system" para asegurar el éxito en la taquilla, y de esa forma creó un obstáculo para el surgimiento de companías teatrales locales.

Por otra parte, se vio la forma en que la creación de un sindicato de actores y la llegada al país de artistas europeos que se radicaron en Buenos Aires en los años previos a la segunda guerra mundial fortalecieron el campo teatral local. Asimismo, algunos artistas devinieron en empresarios teatrales y buscaron orientar sus empresas hacia un teatro de mayor calidad artística, se alejaron de la tendencia hacia el shund que primaba en los escenarios de la época. No obstante, estos teatros continuaron dependiendo del "star system" y de la recaudación de la taquilla, por lo que no lograron contribuir con el surgimiento de una compañía teatral local que pudiera funcionar dentro del circuito empresarial y ocupar un lugar junto a los elencos encabezados por las figuras visitantes. De esta forma, si bien las empresas teatrales que surgieron en esos años se preocuparon por lograr el tan ansiado equilibro entre el biznes y el arte, no pudieron, sin embargo, dar solución a la desproporción que existía en el teatro empresarial judío de Buenos Aires entre lo local y lo extranjero. \$ 